\title{
Thaparocleidus devraji (Gusev, 1976) Lim, 1996, Infesting Ompok bimaculatus (Bloch, 1794) (Siluriformes: Siluridae): Morphological and Molecular Study
}

\author{
Saroj Rajvanshi ${ }^{1}$, Nirupama Agrawal ${ }^{1}$, Manoj Kumar Upadhyay ${ }^{2, *}$ \\ ${ }^{1}$ Department of Zoology, University of Lucknow, Lucknow, 226007, Uttar Pradesh, India \\ ${ }^{2}$ Scientist C, Biotech Park, Lucknow \\ *Corresponding Author: drmkupadhyay@gmail.com
}

Copyright $(2014$ Horizon Research Publishing All rights reserved.

\begin{abstract}
Thaparocleidus devraji [8, 12] from Ompok malabaricus [27] was established by Gusev [8]. However, its description was based only on the hard parts. On a careful examination of its live specimens from an additional host and a new locality i.e. river Gomti of Lucknow, structural details of the parasite were added, including its egg. Furthermore, phylogenetic relationship was also established with other Indian species of this genus using Urocleidus similis and Ancyrocephalus paradoxus included in an out group. Sequence analysis of partial 28S rDNA had been done using Minimum evolution (ME), Neighbour-joining (NJ) and UPGMA method of MEGA 5 (Molecular Evolutionary Genetics Analysis-5, Tamura et al. [20]). Furthermore, secondary RNA structure, centroid structure, ss- count, energy dot plot and motif identification had been done, along with GC calculation (for conservedness). All the species of this genus under study, had been found morphologically distinct (reproductive and haptoral armature). The morphological distinctions had been supported by genetical evidences. The results of phylogeny had shown that all the species (understudy) are genetically distinct and T.devraji had monophyletic origin.
\end{abstract}

Keywords Thaparocleidus, Ompok bimaculatus, Phylogenetic Analysis

\section{Introduction}

Ompok bimaculatus (Bloch 1794), variously known as butter fish, two spot glass catfish or pabda catfish. It inhabits in freshwater body of plains and sub montane regions of India, Pakistan, Sri Lanka, Bangladesh and Myanmar. Till now only three species of the genus Thaparocleidus had been reported from this host viz., Thaparocleidus malabaricus [8, 12] (earlier described from Ompok bimaculatus, type locality not given), Thaparocleidus octotylus [10, 12] (from Ompok Pabda at Hyderabad) and
Thaparocleidus devraji (from Ompok. malabaricus from Bhavanisagar reservoir). In the present work, only Thaparocleidus devraji had been included whose description from Ompok bimaculatus, was based only on hard parts. On careful examination of its live specimens, from an additional host, in a new locality river Gomti of Lucknow district, structural details of the parasites were observed. Differentiation of a species genetically as well as morphological was one of the most important aims of modern biology, which effectively determines inter as well as intraspecies variations. Molecular tools, using molecular data of conserved domain was being used for rapid and accurate assessment of species. In monogenes, sequences of ribosomal subunits were widely used to infer phylogenetic relationships at the level of families and subfamilies [13, 14, 15] and also to investigate the evolutionary association between the parasites and their hosts $[8,16]$. The structural parameters of the 28S secondary structure (geometrical parameters, bond energy and base composition) were used to study phylogenetic relationships among the species [1]. The topology of secondary structure (type/ number/position of loops and single/double stranded portion) was also considered important diagnostic genetic characters for species identification [9, 16 and 24]. Chaudhary and Singh [3] gave secondary structures and phylogenetic utility of the ribosomal subunit (28S) in Thaparocleidus parvulus $[8,12]$, parasitizing gill filaments of Mystus vittatus in India. In the present work, being a distinct valid species, Thaparocleidus devraji is described in detail because the original description lacked whole mount drawings etc. Its phylogeny on molecular basis is also established along with other Indian species of the genus Thaparocleidus (Thaparocleidus parvulus, Thaparocleidus sp. 1 HS, Thaparocleidus sp. 2 HS, Thaparocleidus sp. HSS, retrieved from Gen Bank). Furthermore, motif identification, secondary RNA structures, centroid structure, ss- count, and energy dot plot were generated along with GC percentage, using a GC calculator for species differentiation (earlier work of Chaudhary and Singh [3, 4], Chairy et al., [5] was for genera differentiation). 


\section{Materials \& Methods}

Fishes were collected from River Gomti at Lucknow $\left(26.84^{\circ} \mathrm{N} 80.94^{\circ} \mathrm{E}\right)$, Uttar Pradesh; India. Live hosts were also bought from fish markets and maintained in glass aquaria. Hosts were identified by Fishbase [28]. Gills of freshly dead hosts were examined fresh as well as fixed $(3 \%$ formaline diluted with lukewarm water). Parasites were dislodged with micro needles in glass petri-dishes and studied under a phase contrast microscope (Olyumpus BX 51). The methods for staining, mounting and illustrating the dactylogyrids were as described by Kritsky et al. [11] and numbering of hooks was that of Kulweic. Measurements were taken in $\mu \mathrm{m}$, using a calibrated micrometer, following the procedure and terminology of Gusev [8]; means were followed by the range and the number (n) of specimens measured in parentheses. Unstained glycerine mounts, sealed with selant, were used for measurement of soft as well as hard parts. Measurements and illustrations were made with the help of images taken with camera (Olyumpus-Photometrics Coolsnap), attached with microscope, using Image-ProExpress 6.0 (for Image analysis).

\subsection{DNA Isolation}

Single parasite was collected in absolute ethanol for DNA extraction. Total DNA was extracted from the collected parasite using Qiagen's Dneasy Blood and Tissue Kit (Cat. No. 69504) by following protocol as per DNA extraction kit with slight modifications.

\subsection{Polymerase Chain Reaction (PCR)}

Partial 28S rDNA region of Thaparocleidus devraji was amplified in an Eppendorf Master Cycler Personal (PCR machine: Polymerase chain reaction machine) using forward (5'- ACCCGCTGAATTTAAGCAT-3') and reverse (5'-CTCTTCAGAGTACTTTTCAAC-3') primers [2]. The reaction volume was $25 \mu \mathrm{l}$, containing $2 \mu \mathrm{l}$ PCR buffer (10X), $0.5 \mu \mathrm{l}$ dNTPs $(10 \mathrm{mM}), 0.5 \mu 1$ forward primer (19.6 nMol.), $0.5 \mu 1$ reverse primer $(31.9 \mathrm{nMol}$ ) $), 0.5 \mu \mathrm{l}$ Taq polymerase $(5$ Units), $1 \mu \mathrm{l} \mathrm{MgCl} 2$ (25 mM), $5 \mu 1$ genomic DNA and $15 \mu \mathrm{l}$ miliQ water. PCR conditions were $95^{\circ} \mathrm{C}$ for $4 \mathrm{~min}$. (initial denaturation), followed by 35 cycles of $95^{\circ} \mathrm{C}$ for $1 \mathrm{~min}$. (denaturation), $55^{\circ} \mathrm{C}$ for $45 \mathrm{sec}$ (annealing), $72^{\circ} \mathrm{C}$ for $30 \mathrm{Sec}$. (extention), $72^{\circ} \mathrm{C}$ for $7 \mathrm{~min}$. (Final extention), hold at $72^{\circ} \mathrm{C}$ for $4 \mathrm{~min}$. PCR products were checked on $1.5 \%$ agarose gels in TAE buffers stained with ethidium bromide (EtBr) and visualized under UV light. Amplicons were sequenced with the same primers using automated sequencer (Inst Model/Name: 3730xl/-SYNGENE-373XL/-140362-004 of Applied Biosystems).

\subsection{Data Analysis}

Sequencing products were subjected to BLAST (Basic Local Alignment Search Tool) for homology search. Multiple sequence alignment was performed using Clastal W
[19]. The sequence of query species (Thaparocleidus devraji) was compared with retrieved sequences (Table 2) to infer phylogenetic relationship among them. Sequence data (obtained/retrieved) were analyzed using minimum evolution and neighbour-joining methods of MEGA 5 for generating phylogenetic trees. The robustness of the inferred phylogeny were assessed using bootstrap values at 1000 replications. Genetic relatedness among the analyzed monogenes was because of conserved as well as identical regions. Secondary structure of RNA was reconstructed from obtained sequence of partial $28 \mathrm{~S}$ ribosomal region. Thus the inferred secondary structure and (folding pattern) significantly improved the phylogenetic studies. Further energy dot plot for searching all possible folding (with energy values) and ss-count were used to predict propensity of each base respectively. Percentage of Guanocine (G) and Cytocine (C) was calculated using GC calculator [26]. Secondary RNA structure, ss-count, and energy dot plot was generated using Mfold [24]. Secondary structure and centroid structure of each species was also generated for species discrimination [17, 21, 22]. Motifs were predicted by MEME [18]. Sequence (partial 28S rDNA) of Thaparocleidus devraji was submitted to Genbank under accession number KC962229.

\subsection{Redescription}

Body 657 (398-823; n=10) long, maximum width 126 $(78-150 ; n=10)$ at mid length (Figure 1). Cephalic region well developed; cephalic lobes 2 pairs, having 2 pairs of eye spots, posterior pair larger, accessory granules present; pharynx spherical $41(24-55 ; n=10)$ in diameter; oesophagus short to non-existent.

Testis $98(65-136 ; n=10)$ long, maximum width at mid length of testis, $55(35-75 ; n=10)$; vas deferens loops left intestinal caecum; seminal vesicle sigmoid dilation of vas deferens. One pair prostatic reservoirs, opening at the base of copulatory complex. Copulatory complex of a sclerotised copulatory tube, having about one and half clockwise coil, $116(93-133 ; n=10)$ long and proximally articulated massive accessory piece (Figure 1.3) in two pieces; measuring 15 $(10-18 ; n=10)$ and $21(16-25 ; n=10)$ in length. Ovary round to oval, inter-caecal, $99(70-130 ; n=10)$ long, maximum width at mid length, $58(50-62 ; n=10)$. Vagina lightly sclerotised (Figure 1.7). Seminal receptacle round to oval. Vitellaria dense, throughout trunk, except in the regions of reproductive organs.

Haptor $118(90-170 ; n=10)$ long, $97(74-130 ; n=10)$ wide. Dorsal anchor: outer length $58(53-70 ; n=10)$, inner length 68 $(60-72 ; n=10)$, recurved point $25(20-28 ; n=10)$ (Figure 1.1); dorsal patch $19(18-22 ; n=10)$ (Figure 1.1). Ventral anchor: without roots, outer length $20(18-26 ; n=10)$, inner length 19 $(17-24 ; n=10)$, recurved point $6(6-7 ; n=10)$ (Figure 1.2). Dorsal bar $19(18-22 ; n=10)$ (Figure 1.5). Ventral bar 31 (21-38; n=10) long (Figure 1.4). Seven pairs similar hooks $12(12-13 ; \mathrm{n}=10)$ long (Figure 1.6). Egg round to oval, unipolar, $57(56-58 ; n=5)$ long, $39(37-40 ; n=5)$ wide; single polar filament $9(9-11 ; n=5)$ long (Figure 1.8). 
Table 2. Genbank reference sequences used and their respective information

\begin{tabular}{|c|c|c|c|c|}
\hline S. no. & Parasite & Host & $\begin{array}{c}\text { Accession no. } \\
\text { Reterived (R)/Query (Q) }\end{array}$ & Country \\
\hline 1 & Thaparocleidus parvulus & - & GU014844.1(R) & India \\
\hline 2 & Thaparocleidus sp. 2 HS & Silonia silondia & GU980973.1(R) & India \\
\hline 3 & Thaparocleidus sp. 1 HS & Wallago attu & GU980972.1(R) & India \\
\hline 4 & Thaparocleidus sp. HSS & Wallago attu & JN020351.1(R) & India \\
\hline 5 & Thaparocleidus devraji & Ompok bimaculatus & KC962229(Q) & India \\
\hline 6 & Urocleidus_similis & - & AJ969938.1(R) & Czech \\
\hline 7 & Ancyrocephalus_paradoxus & - & AJ969952.1(R) & Slovakia \\
\hline
\end{tabular}

Syn: Silurodiscoides devraji [8]; Parancylodiscoides devraji [6, 8]

Type host: Ompok malabaricus [27]

Additional host: Ompok bimaculatus [27]

Infection site: Gills

Type locality: Bhavanisagar reservoir, India

Present record and locality: River Gomti, Lucknow

No. of Fish hosts examined: 15

No. of hosts found infected: 6

No. of parasites studied: 25

Prevelance and intensity: Prevalence of Thaparocleidus devraji was $20 \%$ and intensity reached upto 20 to 30 parasites per fish host Specimen studied: 5 Vouchers (w9330/1-w9335/1) were submitted in Helminthological collection of ZSI (Zoological survey of India) Gene sequences: Sequence (partial) of 28S rDNA was submitted in NCBI under accession no. KC962229

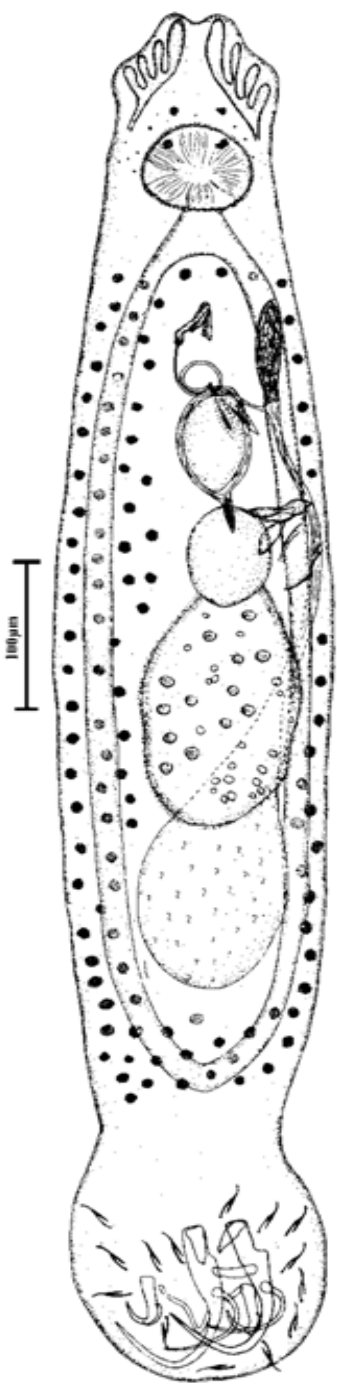

Figure 1. Thaparocleidus Devraji (Gusev, 1976) Lim, 1996
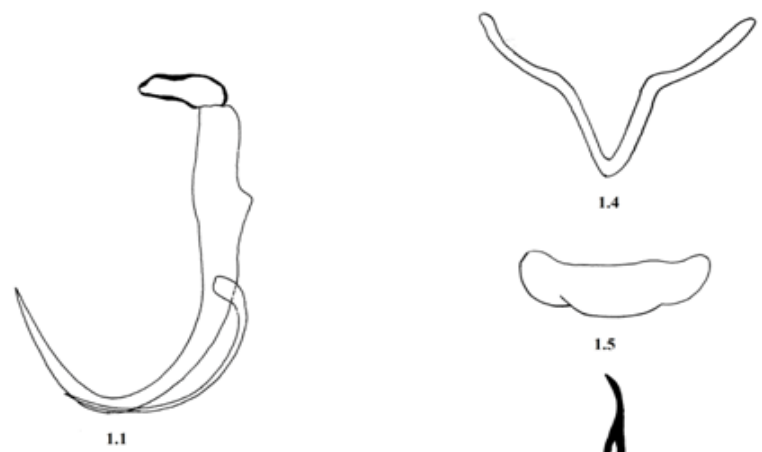

1
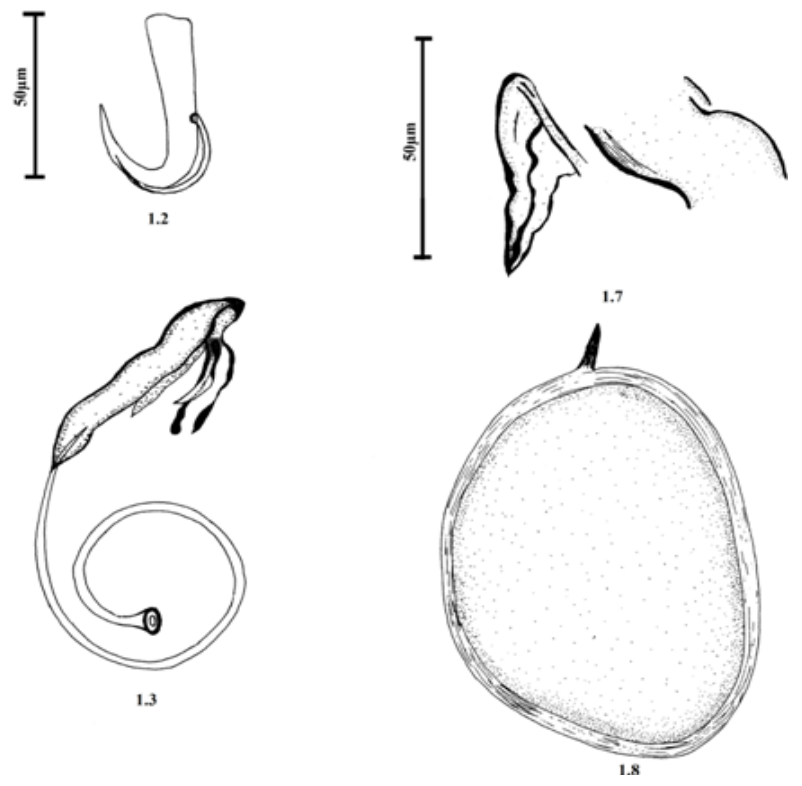

Figure 1.1. Dorsal anchors, 1.2- Ventral anchors, 1.3- Copulatory complex, 1.4- Ventral bar, 1.5- Dorsal bar, 1.6- hook, 1.7- Vaginal armature, 1.8- Egg 


\section{Results AND Discussion}

Thaparocleidus devraji was established by Gusev, [8] as Silurodiscoides devraji from gills of Ompok. malabaricus at Bhavanisagar reservoir, India. Dubey et al. [6] placed it under Parancylodiscoides devraji. Lim [12] considered Thaparocleidus, a senior synonym of Silurodiscoides, transferring this species in Thaparocleius. However, the original description was based only on hard parts and vaginal armature and egg were also not observed, which we could add. We could also observe the detailed soft parts. Of all the known Indian species, the species under study closely resembles with Thaparocleidus octotylus in the comparative morphology of hooks, dorsal patch, copulatory tube and ventral bar, but differs in the structure of dorsal anchor (smaller in Thaparocleidus octotylus), ventral anchor (roots significant in Thaparocleidus octotylus), dorsal bar (longer in Thaparocleidus octotylus), accessory piece of copulatory complex (pincer shaped in T. octotylus but massive in Thaparocleidus devraji. It also differs significantly from Thaparocleidus malabaricus in the structure of copulatory complex, vaginal armature, dorsal anchor, ventral anchor, dorsal patch, dorsal bar and ventral bar. We are of the opinion that it is a distinct and valid species of the genus.

Phylogenetic analysis among Thaparocleidus species (understudy) had been established by Minimum evolution (ME), Neighbour joining (NJ) and UPGMA methods of MEGA 5. The evolutionary trends were generated using sequences of $28 \mathrm{~S}$ rDNA region of five Indian species of genus Thaparocleidus namely Thaparocleidus parvulus, Thaparocleidus sp. 2 HS, Thaparocleidus sp. 1 HS, Thaparocleidus HSS and Thaparocleidus devraji with Urocleidus similis and Ancyrocephalus paradoxus (treated as out group). Thaparocleidus belongs to the sub-family Ancylodiscoidinae and Urocleidus similis and Ancyrocephalus paradoxus to Ancyrocephalinae of the family Dactylylogyridae. All the phylogenetic methods (ME, NJ and UPGMA) showed Thaparocleidus to be of monophyletic origin [14, 15, 23]. These five species showed similar evolutionary pattern by all the three phylogentic methods. Query sequence (Thaparocleidus devraji) evolved from the same node as other species, showing closeness. All the methods formed two clusters for Thaparocleidus. Cluster one further formed two sub clusters. Sub cluster one included
Thaparocleidus parvulus and Thaparocleidus sp. 1 HS and sub cluster two had Thaparocleidus sp. 2 HS. The second cluster included Thaparocleidus sp. HSS and Thaparocleidus devraji. The ME tree (Figure 2) of phylogeny showed $41 \%$ similarity between species of sub cluster one, $26 \%$ between species of sub cluster one and two and $55 \%$ between species of the cluster two. However, NJ (Figure 3) and UPGMA (Figure 4) tree had 40\%, 27\%, 59\% and $42 \%, 41 \% 59 \%$ similarity respectively. The similarity between cluster one and two was 39\% for ML tree. Estimate of average evolutionary divergence of all the five sequence pair was 0.73 . Estimate of pair wise mean lied between 0.65-0.77 (Table 1). Molecular study therefore supported the morphological observations. Thaparocleidus devraji (query sp. )was close to Thaparocleidus sp. HSS. Correct identification and designation of $T$. sp. $1 \mathrm{HS}, T$. sp. 2 HS and $T$. sp. HSS was required for comparison of Indian species.

Table 1. Showing pair wise mean of analysed Indian species of genus Thaparocleidus Jain, 1952

\begin{tabular}{|c|c|c|c|c|c|c|}
\hline Thaparocleidus parvulus & & & & & & \\
\hline Thaparocleidus sp. 2 HS & 0.66 & & & & & \\
\hline Thaparocleidus sp. 1 HS & 0.64 & 0.66 & & & & \\
\hline Thaparocleidus HSS & 0.71 & 0.74 & 0.73 & & & \\
\hline Thaparocleidus devraji & 0.73 & 0.68 & 0.77 & 0.65 & & \\
\hline Urocleidus similis & 0.79 & 0.67 & 0.79 & 0.77 & 0.77 & \\
\hline Ancyrocephalus_paradoxus & 0.76 & 0.8 & 0.73 & 0.73 & 0.83 & 0.74 \\
\hline
\end{tabular}

Reconstructed secondary structure of RNA (Figure 9) of partial 28S ribosomal region of Thaparocleidus devraji had highest negative free energy $\Delta \mathrm{G}-97.60 \mathrm{kcal} / \mathrm{mol}$. It was $-101.10,-226.90,-227.30$ and -269.10 in Thaparocleidus parvulus (Figure 5), Thaparocleidus sp. 1 HS (Figure 6), Thaparocleidus. sp. 2 HS (Figure 7) and Thaparocleidus sp. HSS (Figure 8) respectively. The highest negative free energy of hairpin, bulge, multi, interior and external loops for Thaparocleidus parvulus was 31.6, 1.80, 7.5, 11.9 and -11.50 respectively. Thaparocleidus sp. 1 HS had 62.8, 20.5, 9.8, 37.4, -18.90, Thaparocleidus sp. 2 HS had 58.5, 24.1, 9.8, 39.4, -14.70, Thaparocleidus sp. HSS had 54.4, 22.8, 26.6, 48.4, -9.00 and Thaparocleidus devraji had 29.7, 3.10, $5.10,21.4$ and -8.20 respectively. Remaining energy was contributed by stacking energy (Table 3 ).

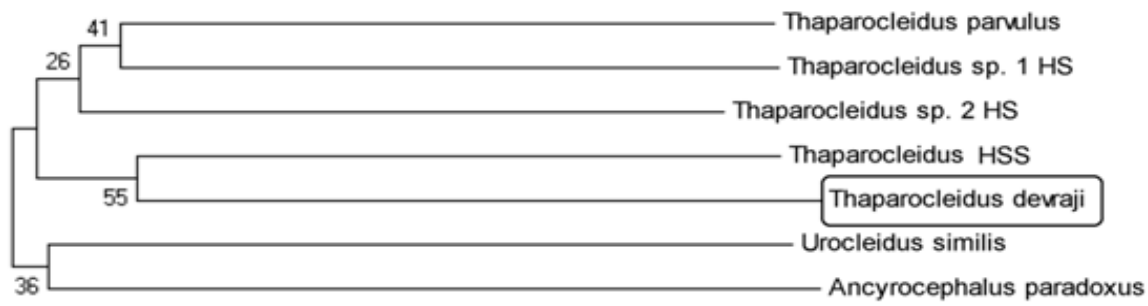

Figure 2. Minimum Evolution method 


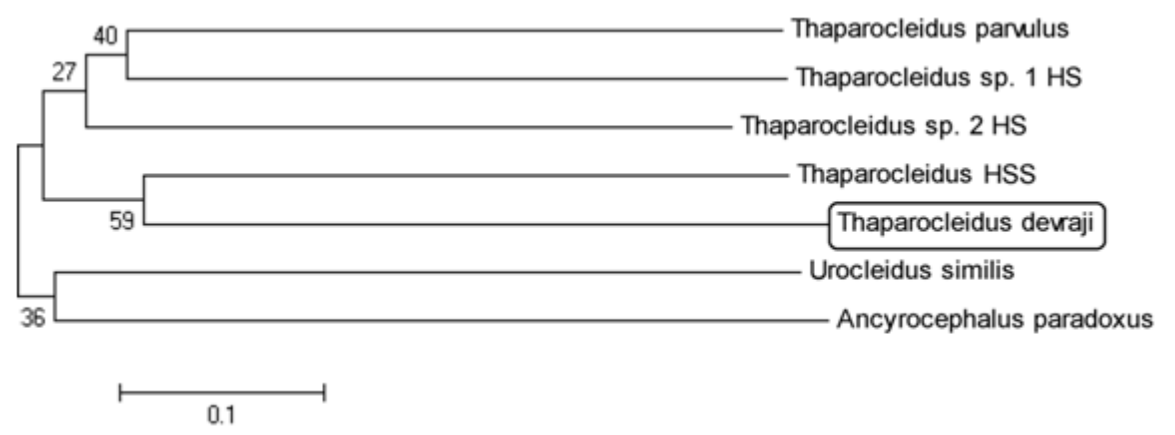

Figure 3. Neighbour-joining method

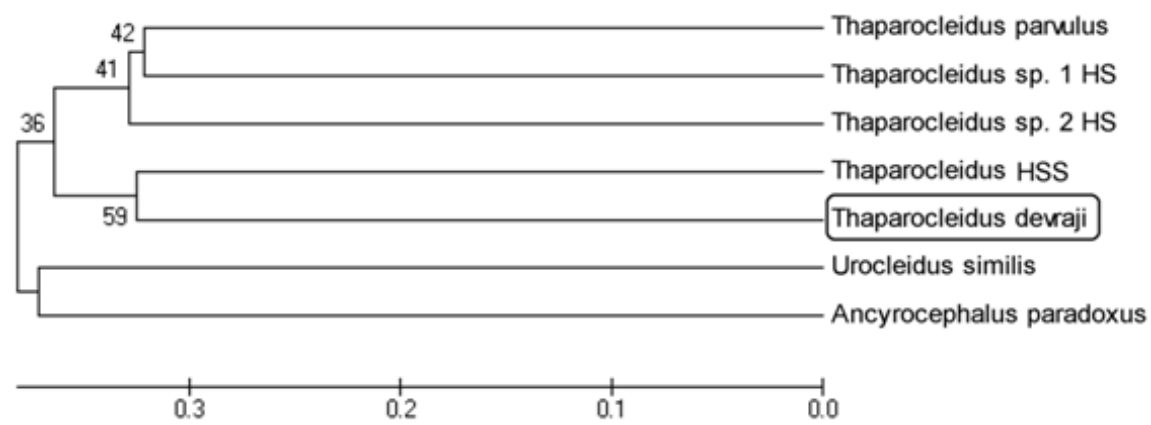

Figure 4. UPGMA method of phylogenetic tree (partial 28S rDNA region of 5 Indian sp. of genus Thaparocleidus with Urocleidus similis and Ancyrocephalus paradoxus (as outgroup) using MEGA 5). 


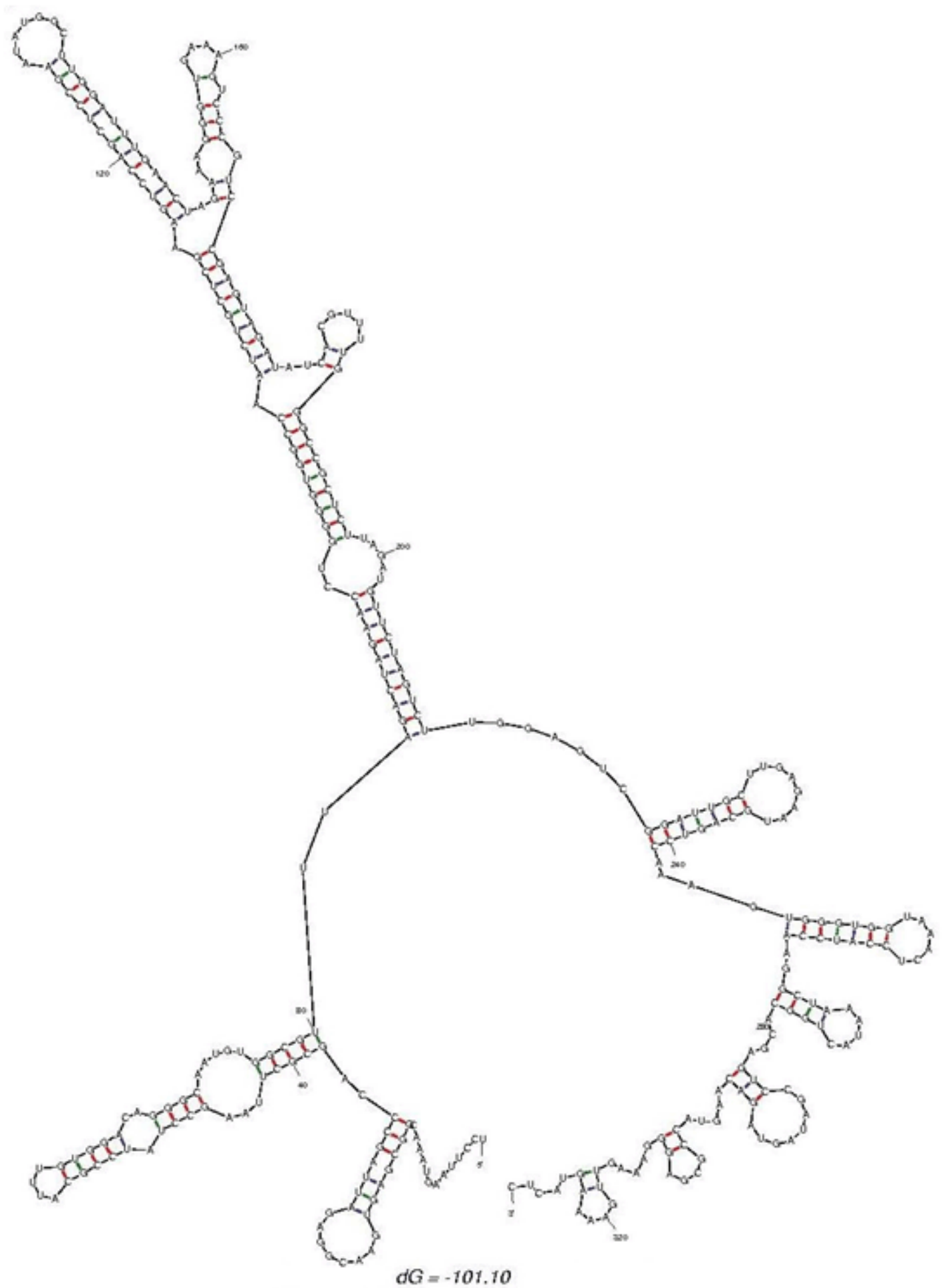

Figure 5. Schematic representation of secondary structure of partial 28S rRNA for T. parvulus 


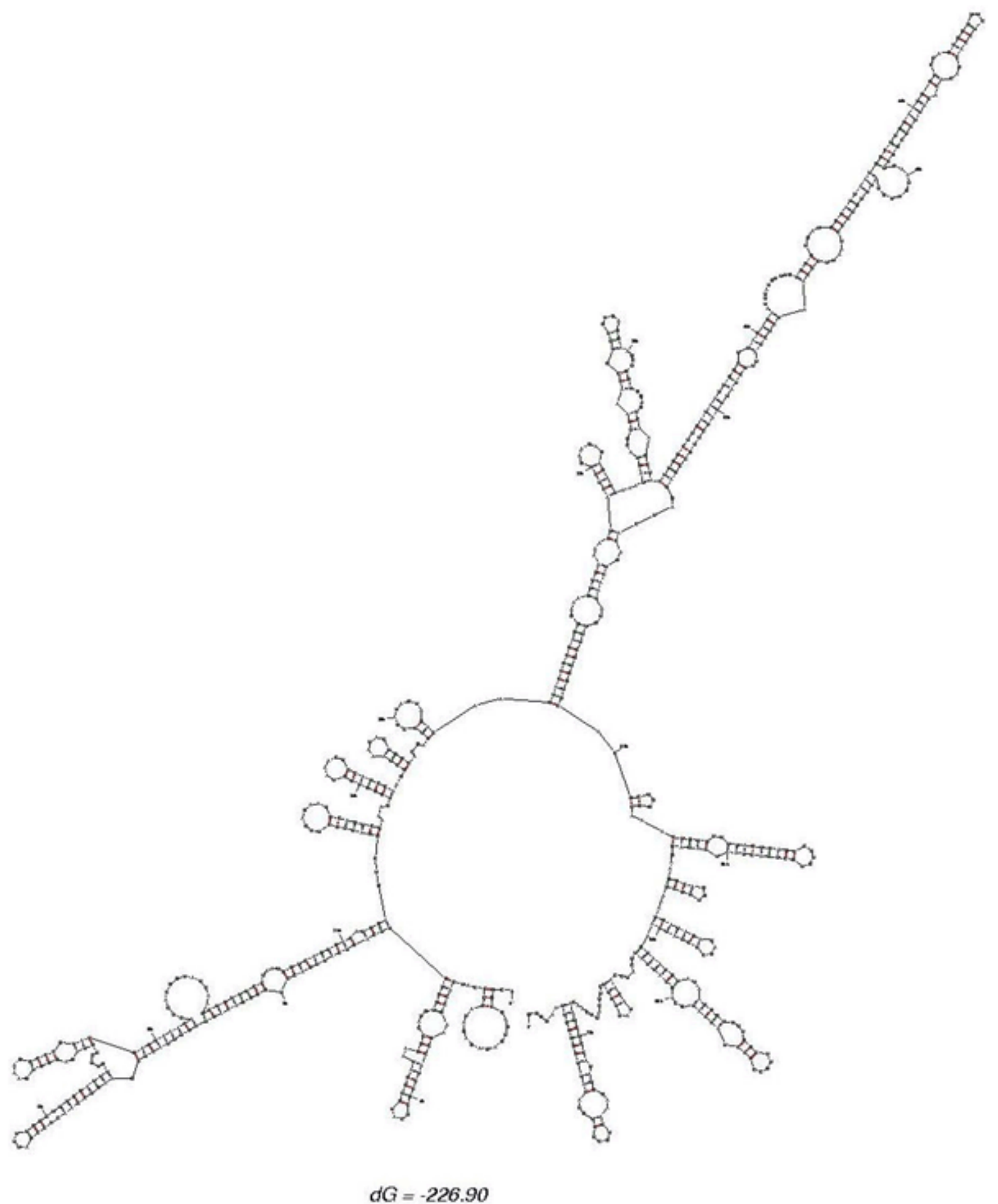

Figure 6. Schematic representation of secondary structure of partial $28 \mathrm{~S}$ rRNA for $T$. sp. 1 HS 


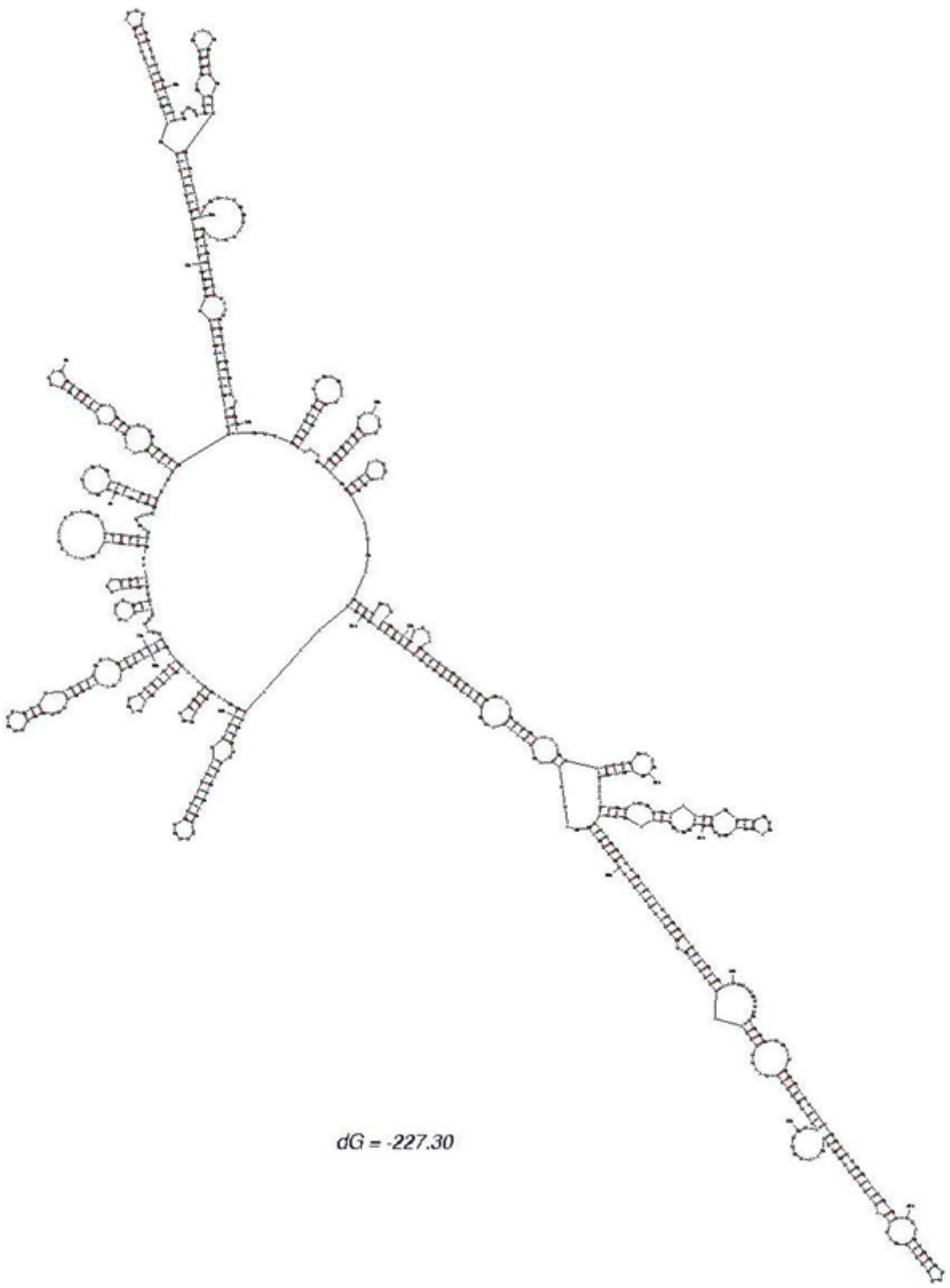

Figure 7. Schematic representation of secondary structure of partial $28 \mathrm{~S}$ rRNA for $T$. sp. 2 HS 


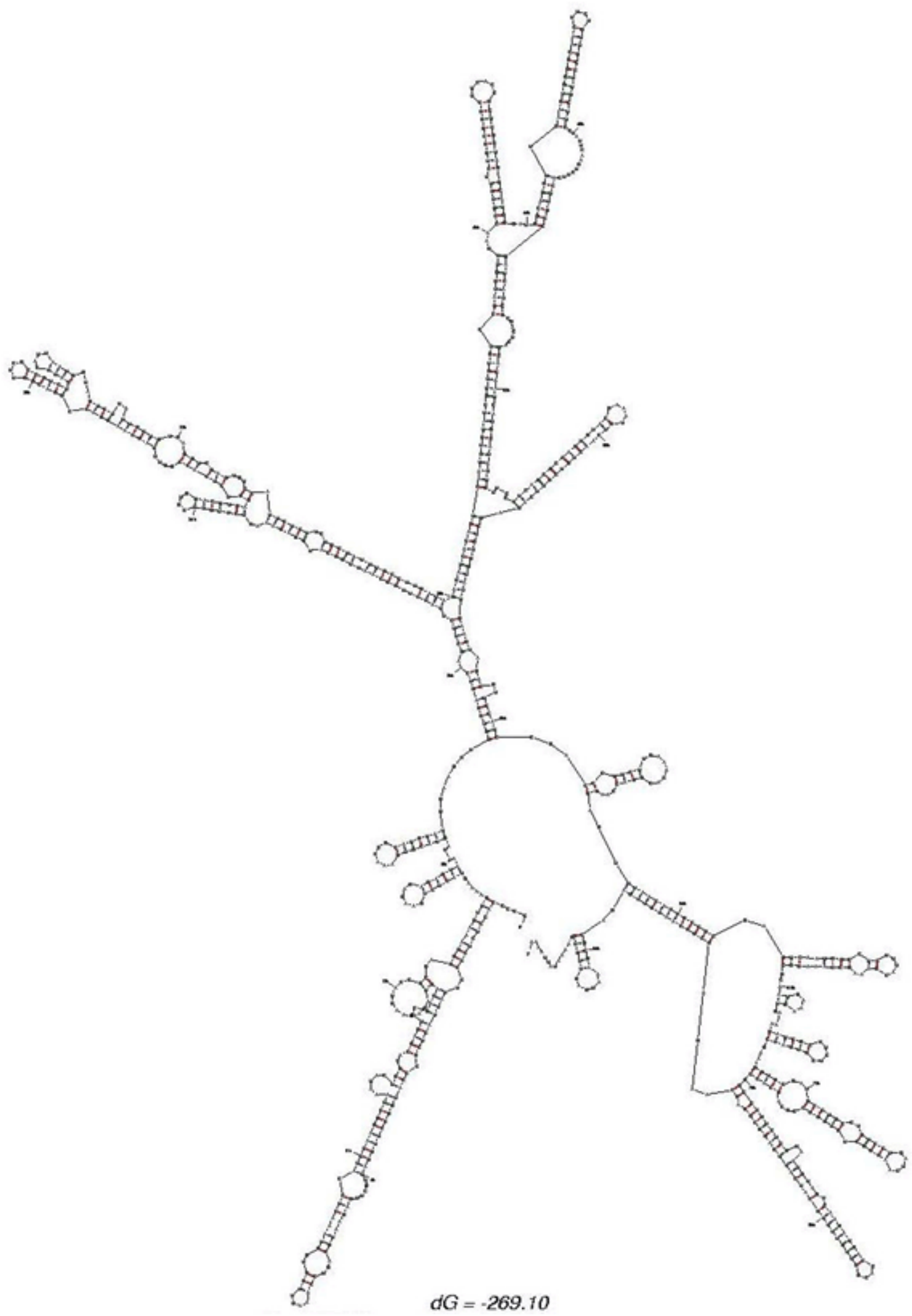

Figure 8. Schematic representation of secondary structure of partial $28 \mathrm{~S}$ rRNA for $T$. sp. HSS 


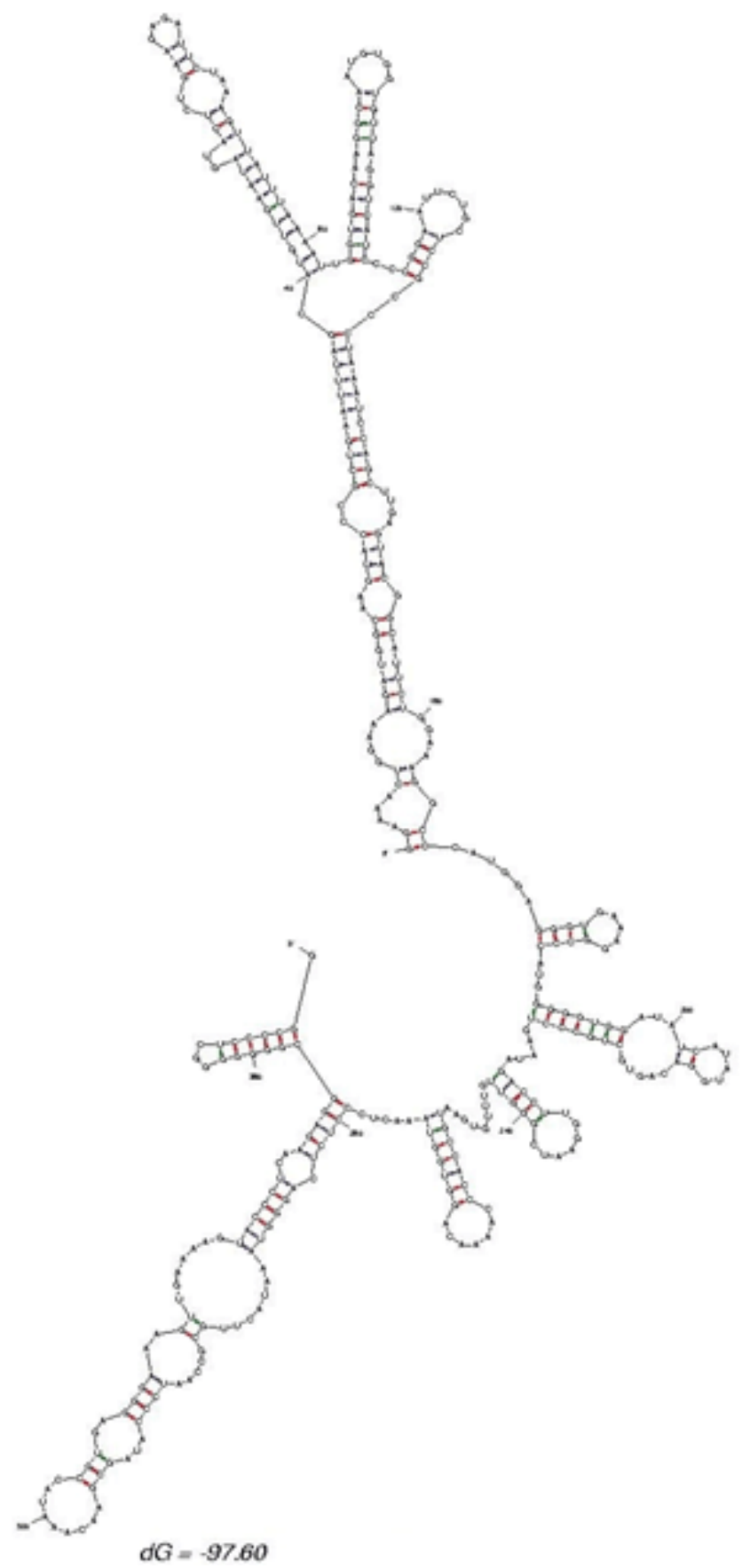

Figure 9. Schematic representation of secondary structure of partial $28 \mathrm{~S}$ rRNA for $T$. devraji 
The order of loop preference (descending order) in constructed. RNA secondary structure of Thaparocleidus devraji had interior loop (13), hairpin loop (9) followed by bulge loop (1) multi loop (1) and external loops (1). In Thaparocleidus parvulus, it was hairpin, interior, multi, bulge and external. In Thaparocleidus sp. 1 HS interior, hairpin, bulge, multi and external loop. However, in Thaparocleidus sp. 2 HS and Thaparocleidus sp. HSS, it was similar i.e interior, hairpin, bulge, multi and external (Figure 10). The centroid structures for Thaparocleidus parvulus and Thaparocleidus sp. 1 HS, Thaparocleidus sp. 2 HS, Thaparocleidus sp. HSS and Thaparocleidus devraji showed bases along the circle. The topology of RNA secondary structures (geometry of base pairing) of each species showed distinct highest negative free energy (sum of the free energies of its all loops), free energy of a loop is independent of all other loops. Number, position and types of loop were also different. Thus, RNA secondary structures are also significant in the identification of specie .Since, the highest negative free energy and topology of RNA secondary structures is species specific $[3,4,5]$.

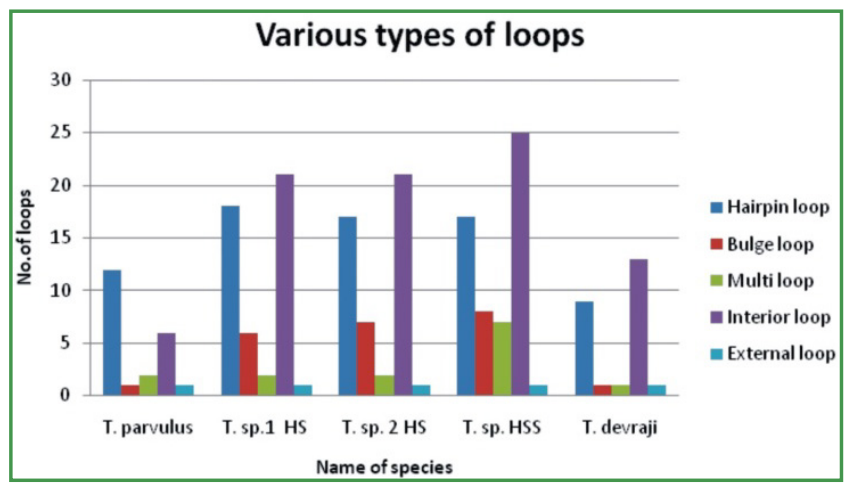

Figure 10. Camparative bar chart showing the number and type of loops in Thaparocleidus species

The base pairing (helices) were shown in the form of arcs. The arc pattern was quite different in all the five species (Figure 11, 12,13, 14, 15). The centroid structures of each species of Thaparocleidus showed different helix pattern (base pairing). Different species never showed similar topology of RNA structure and arc pattern and could additionally be utilized in species identification. Similar interpretations were given by Chaudhary and Singh $[3,4,5]$

The GC content within the sequence is responsible for the conservedness as reported by earlier workers Chaudhary and Singh $[3,4,5]$. Percentage of GC lies between $45 \%$ to $51.2 \%$ in species understudy. Thaparocleidus devraji had $182 \mathrm{GC}$ (48.9\%) and 190 AT, out of 372 nucleobases. Thaparocleidus parvulus had 162 GC (49.2\%) and 167 AT/329, Thaparocleidus sp. 1 HS had 341 GC (45\%) and 417 AT/758, Thaparocleidus sp. 2 HS had 339 GC (45.1\%) and 412 AT/751 and Thaparocleidus sp. HSS had 427 GC $(49.3 \%)$ and $439 \mathrm{AT} / 866$.

The energy dot plot (Figure 16) represented superposition of all possible folding in Thaparocleidus devraji. Different colours were, therefore, used to indicate varying levels of sub optimality. Chairy et al., [5] have used energy dot plot for species discrimination of Dactylogyroides loongicirrus. $D$. longicirrus had different optimal energy from $T$. devraji [4].

The ss-count of Thaparocleidus devraji (Figure 17) showed propensity of each base of 372 nucleobases to be single stranded, within 24 times folding. However, Dactylogyrus longicirrus had 738 nucleobases [4].

The sequences of all the five species of Thaparocleidus were aligned to predict the consensus region, represented by brackets (Figure 18). However, consensus profile was grey in colour (given as bottom line in each alignment row).

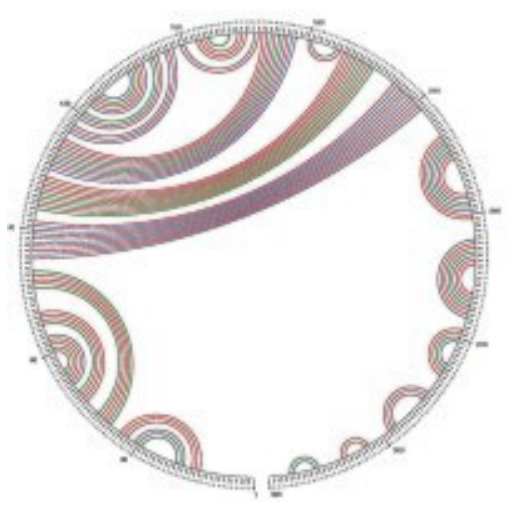

Figure 11

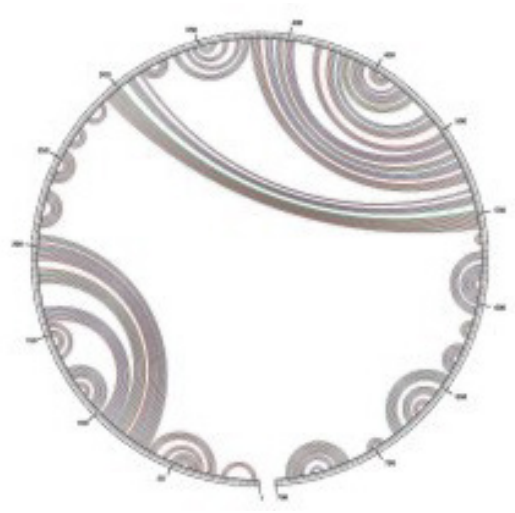

Figure 12

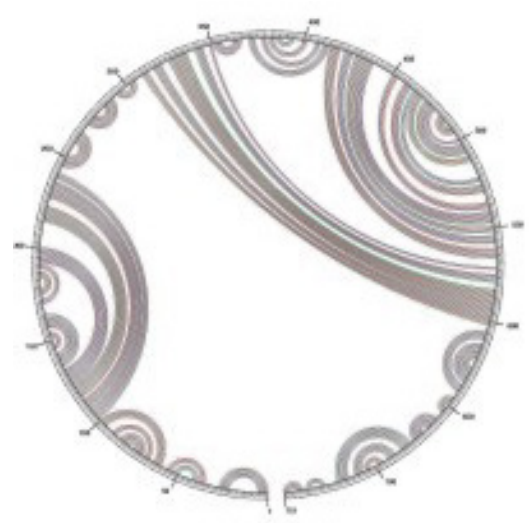

Figure 13 


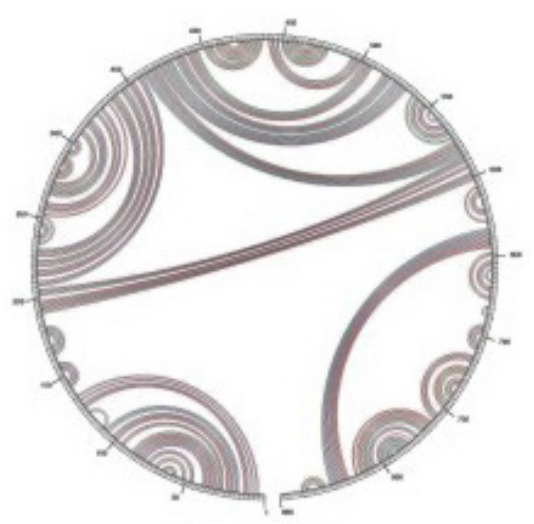

Figure 14

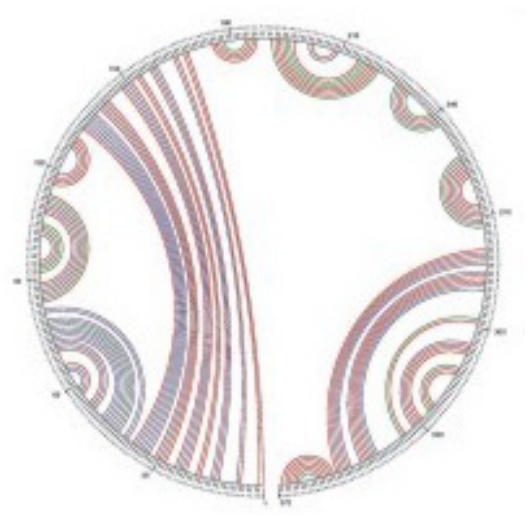

Figure 15

Figure 11., 12., 13., 14. and 15. Comparative centroid structures of $T$. parvulus, $T$. sp. $1 \mathrm{HS}, T$. sp. 2 HS, $T$. sp. HSS and $T$. devraji respectively

Three motifs were found common in these five species (Figure 25). The width of motif one, two and three was 50, 50 and 40 nucleotide bases respectively. Motif one, two and three were coded as green, deep blue and red respectively. Frequency of each motif varied per species (Figure 26).
Motif one (Figure 19) was repeated twice in all the five species. Motif two (Figure 20) four times in Thaparocleidus sp. 1 and Thaparocleidus sp.2, three times in Thaparocleidus sp. HSS. However, this was absent in Thaparocleidus pravulus and Thaparocleidus devraji. Motif three (Figure 21) was repeated four times again in Thaparocleidus sp. 1 and Thaparocleidus sp.2, twice in Thaparocleidus pravulus and Thaparocleidus devraji and once in Thaparocleidus sp. HSS. Regular expression of motif one was [CAT][TA][CG][GA][GA][TC][CG]GAT [AT]G[CT][TA][TG[AG][CA][AG]A[AG]T[AG]C[CA]G[ $\mathrm{CT}][\mathrm{CG}][\mathrm{AC}][\mathrm{AG}][\mathrm{AG}][\mathrm{AG}][\mathrm{AG}][\mathrm{AT}][\mathrm{AG}] \mathrm{G}[\mathrm{GT}] \mathrm{TG}[\mathrm{AG}$ ][AT]AA[AG][CT][AT]C[CT][CA]. However this expression of motif two and three was [GC]T[CG][GAT][TAG]GC[TC]A[CT]TT[AG]TCTTG $[\mathrm{CA}][\mathrm{CT}][\mathrm{GA}] \mathrm{A}[\mathrm{AGT}][\mathrm{TG}][\mathrm{TAG}][\mathrm{TG}] \mathrm{C}[\mathrm{AT}][\mathrm{CT}] \mathrm{A}[\mathrm{GT}][$ CAT][CG]AAT[TA]T[AG]T[AG]T[GT][TG][TC][TG][TC ][GT]G[CGT]GT G[AGT][TCA][CT][CT][AG][CAT][TA] G[ATG][GT][GT][TG][TG]GAA[AT][GA]G[GC]CC[AG] [TG][GA][TCG]G[GA][TG][TG ][ATC][TG][ACT][AC][ $\mathrm{AG}][\mathrm{TC}][\mathrm{CG}][\mathrm{AT}][\mathrm{TCA}]$. The starting point, end point and p-value for each motif were different within the sequences (Figure 22, 23, 24). Lowest p-value for motif one, two and three were also found to be different for each sequence. The combined p-value of all motifs (one, two and three), for each species were also significantly different in all of them.

The present analysis showed that $28 \mathrm{~S}$ ribosomal region exhibited conserved sequence patterns species specific key character (motifs). The number of motif, their frequency, order and position of occurrence within the sequence, were peculiar for them. Thus, it was important to predict species-level variability. 


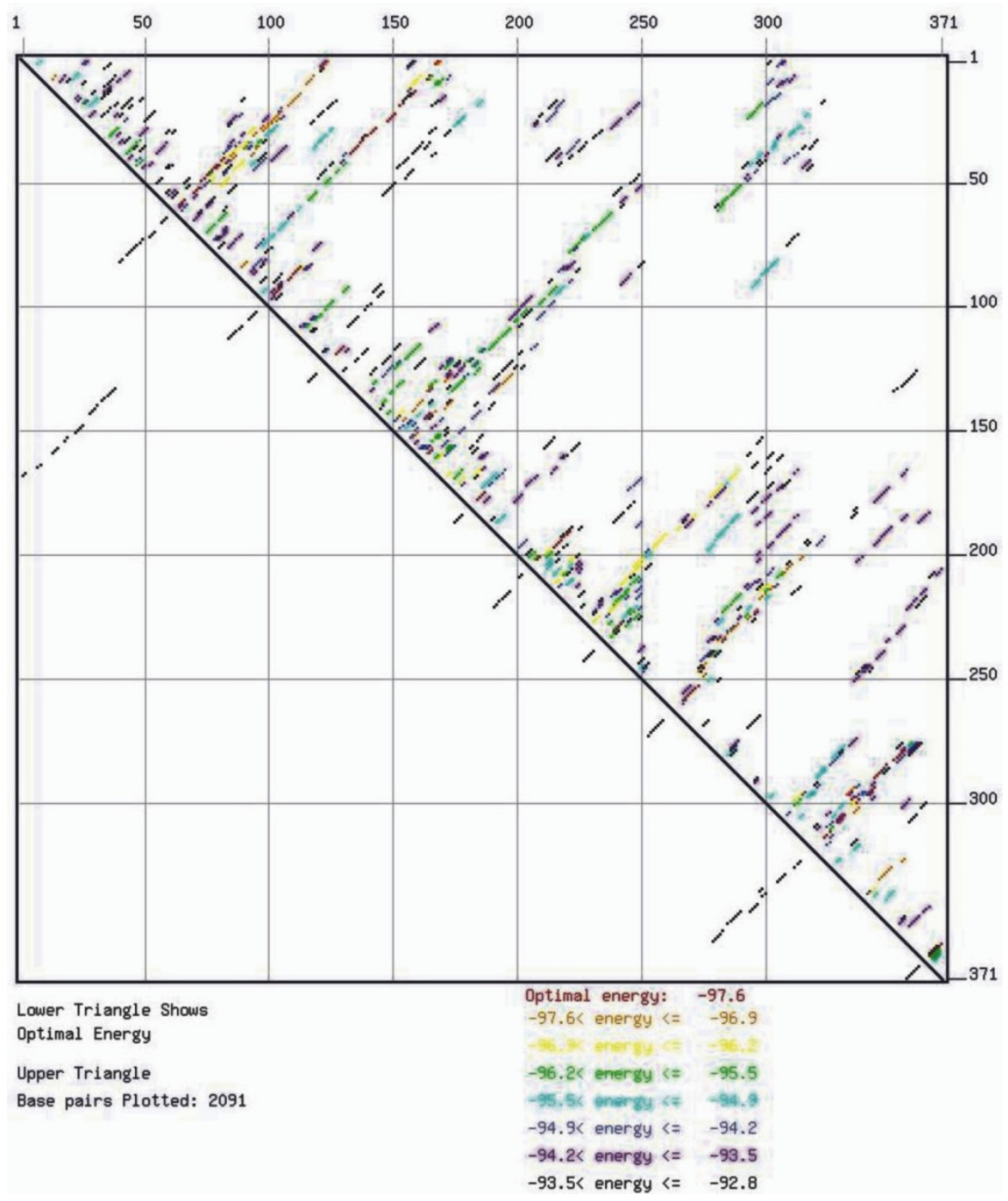

Figure 16. Energy dot plot for T. devraji

ss_count Plot

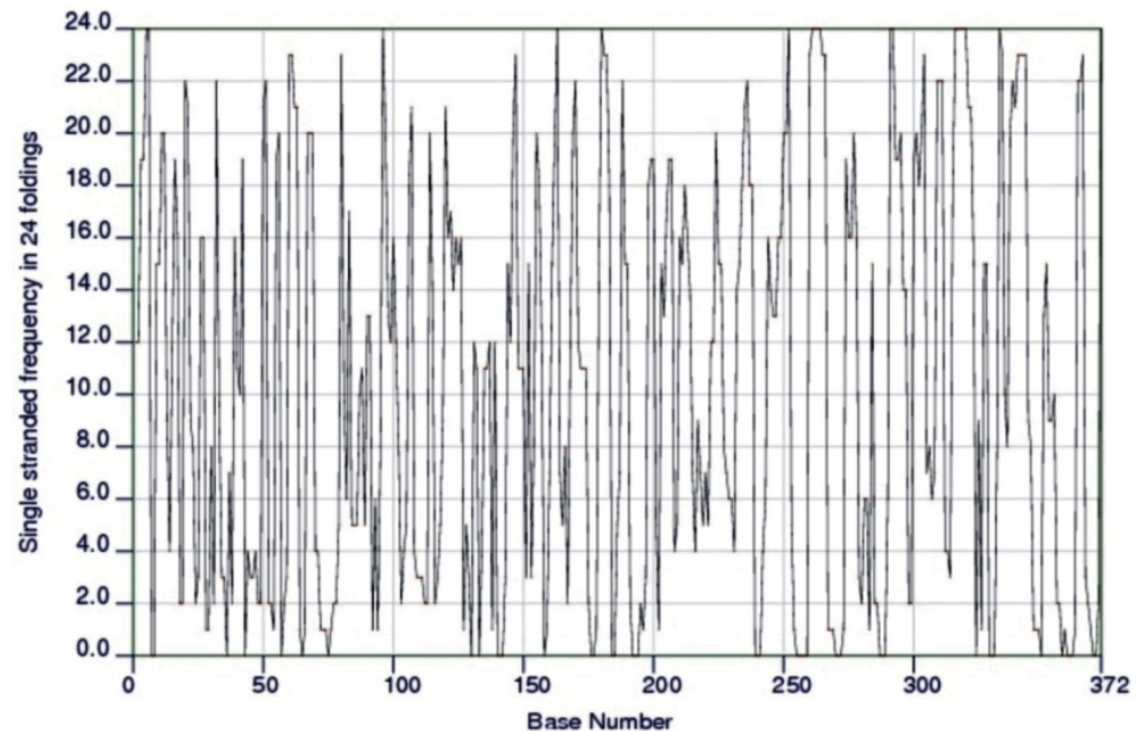

Figure 17. SS count plot of T. devraji 


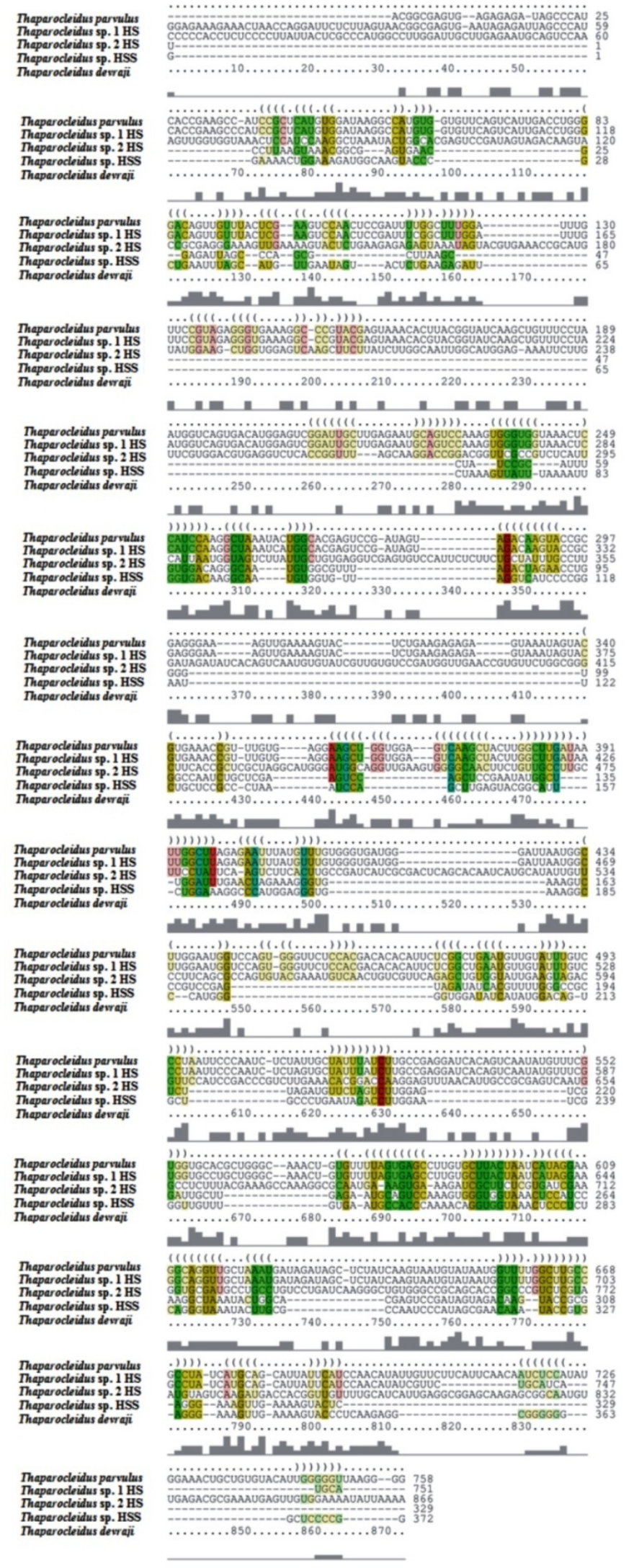

Figure 18. Sequence alignment of Thaparocleidus sp. (understudy) along with consensus profile (grey bars) 


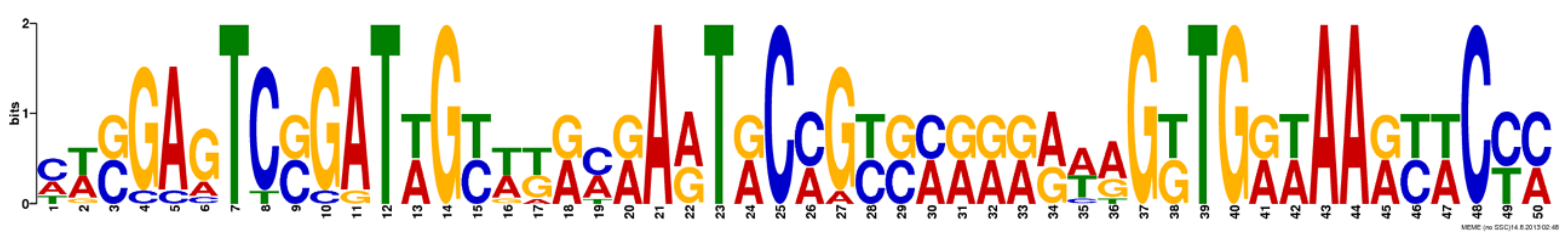

Figure 19. 18 Motif one

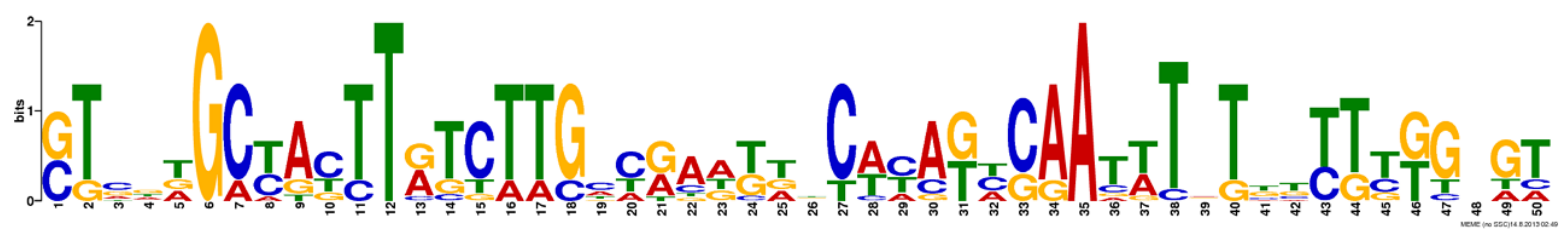

Figure 20. 19 Motif two

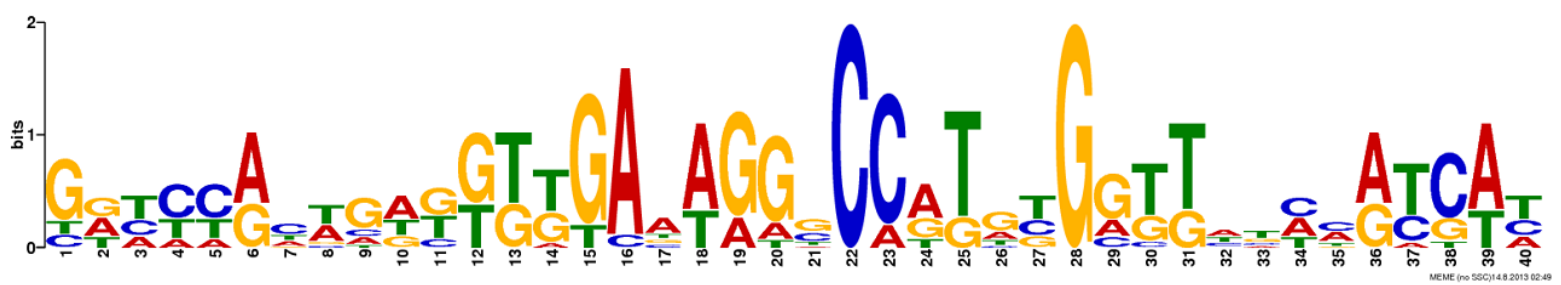

Figure 21. 20 Motif three

\begin{tabular}{|c|c|c|c|c|c|}
\hline Name & Start & $p$-value & & Sites & \\
\hline$T$. sp. HSS & 97 & $4.03 \mathrm{e}-22$ & TAAATACTGG & CACGAGTCCATA $G$ TA GACAAGTACC C CAGGGAAATT GAAAATACTC & TGAAGAGAGA \\
\hline T. sp. $2 \mathrm{HS}$ & 305 & $4.03 \mathrm{e}-22$ & TAAATCATGG & CACGAGTCC GATA $G$ TA $G A C A A G T A C C G C A A G G A A A G T T$ AAAA $G$ TACTC & TGAAGAGAGA \\
\hline T. sp. $1 \mathrm{HS}$ & 270 & $4.03 \mathrm{e}-22$ & TAAATACTGG & CACGAGTCC GATA $G$ TAGACAAGTACCGCAGGGAAGTT GAAAATACTC & TGAAGAGAGA \\
\hline T. parvulus & 280 & $4.03 \mathrm{e}-22$ & TAAATACTGG & CACGAGTCC GATA $G$ TAGACAAGTACC C CAGGGAAATT GAAAA $G$ TACTC & \\
\hline T. sp. $2 \mathrm{HS}$ & 237 & $7.91 \mathrm{e}-21$ & GGTCAGTGAC & ATGGA $G$ TCG GATT GTT $G$ A GAAT CAATCCAAA $G$ T GG GT GTAAACTCCA & TCCAAGGCTA \\
\hline T. sp. $1 \mathrm{HS}$ & 202 & $7.91 \mathrm{e}-21$ & GGTCAGTGAC & 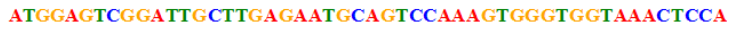 & TCCAAGGCTA \\
\hline T. parvulus & 212 & $1.35 \mathrm{e}-20$ & TGTTCTAGTC & TTGGA $G T C G G A T T$ CTT $G$ A $G A A T G C A G T C C A A A G T G G T G G T A A A C T C C A$ & TCCAAGGCTA \\
\hline T. devraji & 231 & $1.19 \mathrm{e}-18$ & TGAATAGACC & TTGGAATCGGGTTGTTTGTGAATG CCACCCAAAACAGGTG TAAACTCCC & TCTCAGGGTA \\
\hline T. devraji & 299 & $1.29 \mathrm{e}-18$ & TAAATACTTG & CGCCAATCCCATAGCGAACAAATACC $G T$ TAGG GAAA $G T$ TTAAAA $G$ TACCC & TCAAGAGGCG \\
\hline$T$. sp. HSS & 29 & $2.07 \mathrm{e}-18$ & TTACTCGCCC & 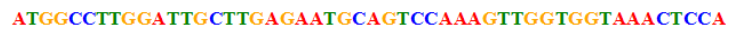 & TCCAAGGCTA \\
\hline
\end{tabular}

Figure 22. 21 Position of motif one in Thaparocleidus sp. 


\begin{tabular}{|c|c|c|c|c|c|}
\hline Name & Start & $p$-value & & Sites & \\
\hline T. sp. $2 \mathrm{HS}$ & 544 & $6.53 \mathrm{e}-19$ & TTCCCAATCT & СТA $G T G$ CTATTTATCTT $G C C G A G G$ ATCACA $G$ TCAATAT $G T T T C G T G G T G$ & CTGCTGGGCA \\
\hline T. sp. $1 \mathrm{HS}$ & 509 & $1.05 \mathrm{e}-18$ & TTCCCAATCT & CTATT $G$ CTATTTATCTT $G C C A$ AGGATCACA $G$ TCAATAT $G T T T C G T G G T C$ & ACGCTGGGCA \\
\hline T. sp. $2 \mathrm{HS}$ & 405 & $7.45 \mathrm{e}-17$ & AGCTGGTGGA & GTCAA $G$ CTACTT $G G$ CTT $G$ ATAATT $G G$ CTTA $G$ A $G$ AATTTAT $G T T T G T G G T$ & GATGGGATTA \\
\hline T. sp. 1 HS & 370 & $7.45 \mathrm{e}-17$ & AGCTGGTGGA & GTCAAGCTACTT $G G$ CTT $G$ ATAATT $G G$ CTTA $G$ A $G$ AATTTAT $G T T T G T G G T$ & GATGGGATTA \\
\hline$T$. sp. HSS & 339 & $8.66 \mathrm{e}-14$ & TGTCCATTCT & СТTCT $G$ CTATTT $G C T T G A T A G A T A T C A C A G T C A A T G T G T A T C G T T G T G T$ & CCGATGGTTG \\
\hline T. sp. 2 HS & 696 & $1.20 \mathrm{e}-13$ & TAATGGTTTT & GGCTTGCCGCCTATCATGCAGCATTATTCATCCAACATATC $G T C T G C A T$ & CATGCA \\
\hline T. sp. $1 \mathrm{HS}$ & 661 & $2.86 \mathrm{e}-13$ & TAATGGTTTT & GGCTTGCCGCCTATCATGCAGCATTATTCATCCAACATATTGTTCTTCAT & TCAACAATCT \\
\hline$T$. sp. HSS & 197 & $3.59 \mathrm{e}-13$ & AGCTGGTGGA & GTCAA $G$ CTTCTTATCTT $G G$ CAATT $G G$ CAT $G G A G A A A T T C T T G T T C G T G G A$ & CGTGAGGTCT \\
\hline T. sp. $2 \mathrm{HS}$ & 114 & $2.94 \mathrm{e}-12$ & AGTCATTGAC & CTGGGGACA GTTGTTTACTCGAA $G$ TCCAACTCCGATTTCG GCTTTGGATT & TGTTCCGTAG \\
\hline T. sp. $1 \mathrm{HS}$ & 79 & $3.53 \mathrm{e}-12$ & AGTCATTGAC & CTGGGGACA GTTGTTTACTCGAA $G$ TCCAACTCC GATTTTGGCTTTGGATT & TGTTCCGTAG \\
\hline$T$. sp. HSS & 452 & $7.78 \mathrm{e}-11$ & GCAGGTTGAA & GTGGGGCAACTTCT $G T T$ CCTT CTTCCTATTCAA G TCTTCACTT GCCGA & TCATCGCGAC \\
\hline
\end{tabular}

Figure 23. 22 Position of motif two in Thaparocleidus sp.

\begin{tabular}{|c|c|c|c|c|c|}
\hline Name & Start & $p$-value & & Sites & \\
\hline T. sp. 2 HS & 70 & $1.68 \mathrm{e}-13$ & CACCGAAGCC & CATCC GTCAT $G$ T $G$ ATAA $G G$ CCAT $G$ T $G$ T $G$ TTCA $G$ TCAT & TGACCTGGGG \\
\hline T. sp. $1 \mathrm{HS}$ & 35 & $1.68 \mathrm{e}-13$ & TCACCGAAGC & CATCC CTCAT $G G G A T A A G G C A T G T G G T$ TTCA GTCAT & TGACCTGGGG \\
\hline T. devraji & 165 & $4.98 \mathrm{e}-13$ & ATTCTGGAAA & GGCCCATGGAGGGTGAAA GGCCCATGGGG T TGGATATCAT & ATGGACAGTG \\
\hline T. sp. 2 HS & 165 & $8.71 \mathrm{e}-12$ & CTTTGGATTT & GTTCC $G$ TA $G$ A $G G G$ T $G$ AAA $G G C C C G$ TAC $G$ A $G$ TAAACACGTA & CGGTATCAAG \\
\hline T. sp. 1 HS & 130 & $2.99 \mathrm{e}-11$ & CTTTGGATTT & GTTCC $G$ TA $G$ A GGGTGAAA GG CCC $G$ TACGAGTAAACACTTA & CGGTATCAAG \\
\hline T. sp. 2 HS & 459 & $1.30 \mathrm{e}-10$ & GTGGGTGATG & GGATTAATGGCTTGGAATGGTCCAGTGGGTTCTCCACGAC & ACACATTCTC \\
\hline T. sp. 1 HS & 424 & $1.30 \mathrm{e}-10$ & GTGGGTGATG & GGATTAATGGCTTGGAATGGTCCAGTGGGTTCTCCACGAC & ACACATTCTC \\
\hline$T$. sp. 2 HS & 600 & $2.32 \mathrm{e}-10$ & GTGCCTGCTG & GGCAAACT $G$ T TTTTA $G T G A G C C T T G T G$ CTTACTAATCAT & AGGAAGGCAG \\
\hline T. sp. 1 HS & 565 & $2.32 \mathrm{e}-10$ & GTGCACGCTG & GGCAAACTGTGTTTTA GT GAGCCTTGTGCTTACTAATCAT & AGGAAGGCAG \\
\hline T. parvulus & 143 & $3.73 \mathrm{e}-10$ & GCTTGGATTT & GAACTA $G$ AAAAGG T TAAA GTCCC $G$ TCC $G$ A $G$ TA $G$ ATATCAC & GTTTTGGGCC \\
\hline T. devraji & 73 & $5.85 \mathrm{e}-10$ & ATTCTAAAGT & TATTTAAAATT $G$ T $G A C A A G G$ CAAT $G$ T GT T TTA G GTCAT & CCCCGGAATT \\
\hline$T$. sp. HSS & 253 & $1.03 \mathrm{e}-09$ & TGGACGTGAG & GTCTCACCGGTTTA GCAA GGACCGGACG GTTCGCCGTCTC & ATTCATTAAT \\
\hline T. parvulus & 49 & $1.86 \mathrm{e}-09$ & CGCTTAAGCC & TATCCGCATTT $G$ TG $G$ ACA $G G G$ CAAT $G T G G C G T T T A G A C T A$ & GAACCTGGGG \\
\hline
\end{tabular}

Figure 24. 23 Position of motif three in Thaparocleidus sp.
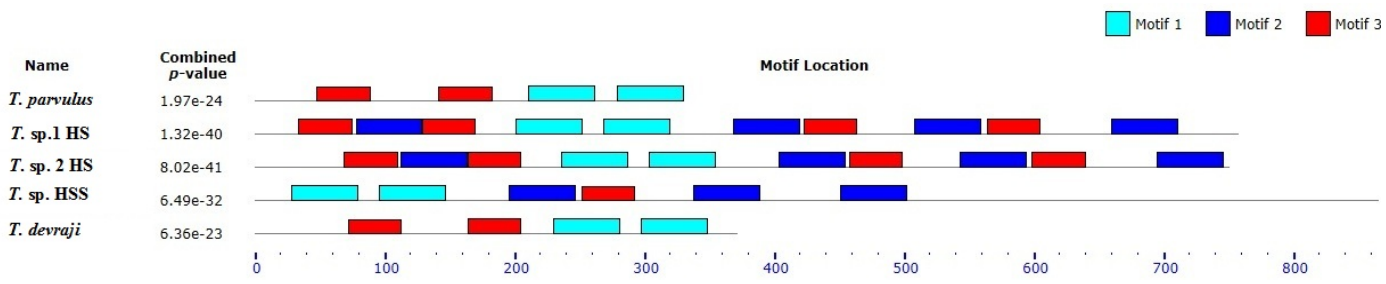

Figure 25. 24 Combined block diagrame of motif in Thaparocleidus sp. 


\section{Bar chart of motifs}

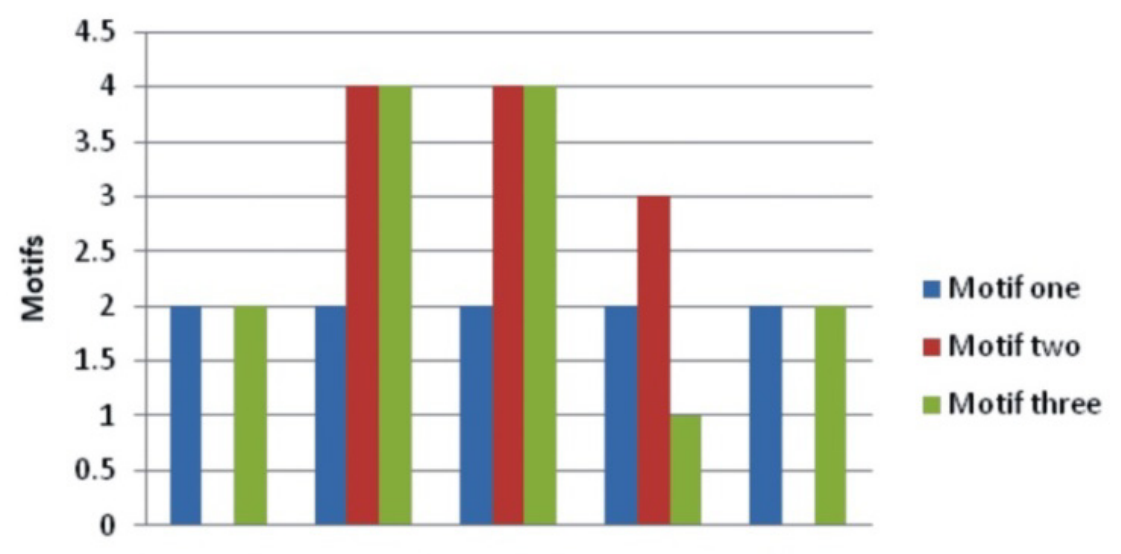

T. parvulus T. sp.1 HS T. sp. 2 HS T. sp. HSS T. devraji

Name of species

Figure 26. 25 Camparative bar chart of motifs for Thaparocleidus sp.

Table 4. Essential information for motifs identification in Thaparocleidus species

\begin{tabular}{|c|c|c|c|c|c|c|}
\hline Motif no. & Parsite & Start point & End point & P-value & Lowest P-value & $\begin{array}{l}\text { Combined p-value } \\
\text { for each species }\end{array}$ \\
\hline \multirow{5}{*}{ Motif one } & T. parvulus & $\begin{array}{l}212 \\
280 \\
\end{array}$ & $\begin{array}{l}262 \\
330 \\
\end{array}$ & $\begin{array}{l}1.35 \mathrm{e}-20 \\
4.03 \mathrm{e}-22 \\
\end{array}$ & $4.03 \mathrm{e}-22$ & $1.97 \mathrm{e}-24$ \\
\hline & T. sp.1 HS & $\begin{array}{l}202 \\
270\end{array}$ & $\begin{array}{l}252 \\
320 \\
\end{array}$ & $\begin{array}{l}7.91 \mathrm{e}-21 \\
4.03 \mathrm{e}-22 \\
\end{array}$ & $4.03 \mathrm{e}-22$ & $1.32 \mathrm{e}-40$ \\
\hline & T. sp. 2 HS & $\begin{array}{l}237 \\
305\end{array}$ & $\begin{array}{l}287 \\
355\end{array}$ & $\begin{array}{l}7.91 \mathrm{e}-21 \\
4.03 \mathrm{e}-22 \\
\end{array}$ & $4.03 \mathrm{e}-22$ & $8.02 \mathrm{e}-41$ \\
\hline & T. sp. HSS & $\begin{array}{l}29 \\
97\end{array}$ & $\begin{array}{c}79 \\
147\end{array}$ & $\begin{array}{l}2.07 \mathrm{e}-18 \\
4.03 \mathrm{e}-22\end{array}$ & $4.03 e-22$ & $6.49 \mathrm{e}-32$ \\
\hline & T. devraji & $\begin{array}{l}299 \\
231 \\
\end{array}$ & $\begin{array}{l}349 \\
281 \\
\end{array}$ & $\begin{array}{l}1.29 \mathrm{e}-18 \\
1.19 \mathrm{e}-18 \\
\end{array}$ & $1.19 \mathrm{e}-18$ & $6.36 \mathrm{e}-23$ \\
\hline \multirow{5}{*}{ Motif two } & T. parvulus & - & - & - & - & \\
\hline & T. sp.1 HS & $\begin{array}{c}79 \\
661 \\
370 \\
509 \\
\end{array}$ & $\begin{array}{l}129 \\
711 \\
420 \\
559 \\
\end{array}$ & $\begin{array}{l}3.53 \mathrm{e}-12 \\
2.86 \mathrm{e}-13 \\
7.45 \mathrm{e}-17 \\
1.05 \mathrm{e}-18 \\
\end{array}$ & $1.05 \mathrm{e}-18$ & \\
\hline & T. sp. 2 HS & $\begin{array}{l}114 \\
405 \\
544 \\
696 \\
\end{array}$ & $\begin{array}{l}164 \\
455 \\
594 \\
746 \\
\end{array}$ & $\begin{array}{l}2.94 \mathrm{e}-12 \\
7.45 \mathrm{e}-17 \\
6.53 \mathrm{e}-19 \\
1.20 \mathrm{e}-13 \\
\end{array}$ & $6.53 e-19$ & \\
\hline & T. sp. HSS & $\begin{array}{l}197 \\
339 \\
452 \\
\end{array}$ & $\begin{array}{l}247 \\
389 \\
502 \\
\end{array}$ & $\begin{array}{l}35.9 \mathrm{e}-13 \\
8.66 \mathrm{e}-14 \\
7.78 \mathrm{e}-11 \\
\end{array}$ & $8.66 \mathrm{e}-14$ & \\
\hline & T. devraji & - & - & - & - & \\
\hline \multirow{5}{*}{ Motif three } & T. parvulus & $\begin{array}{c}49 \\
143 \\
\end{array}$ & $\begin{array}{c}89 \\
183 \\
\end{array}$ & $\begin{array}{l}1.86 \mathrm{e}-09 \\
3.73 \mathrm{e}-10 \\
\end{array}$ & $3.73 \mathrm{e}-10$ & \\
\hline & T. sp.1 HS & $\begin{array}{c}35 \\
130 \\
424 \\
565 \\
\end{array}$ & $\begin{array}{c}75 \\
170 \\
464 \\
605 \\
\end{array}$ & $\begin{array}{l}1.68 \mathrm{e}-13 \\
2.99 \mathrm{e}-11 \\
1.30 \mathrm{e}-10 \\
2.32 \mathrm{e}-10 \\
\end{array}$ & $1.68 \mathrm{e}-13$ & \\
\hline & T. sp. 2 HS & $\begin{array}{c}70 \\
165 \\
459 \\
600 \\
\end{array}$ & $\begin{array}{l}110 \\
205 \\
499 \\
640 \\
\end{array}$ & $\begin{array}{l}1.68 \mathrm{e}-13 \\
8.71 \mathrm{e}-12 \\
1.30 \mathrm{e}-10 \\
2.32 \mathrm{e}-10 \\
\end{array}$ & $1.68 \mathrm{e}-13$ & \\
\hline & $T$. sp. HSS & 253 & 293 & $1.03 \mathrm{e}-09$ & $1.03 \mathrm{e}-09$ & \\
\hline & T. devraji & $\begin{array}{c}73 \\
165\end{array}$ & $\begin{array}{l}113 \\
205\end{array}$ & $\begin{array}{l}5.85 \mathrm{e}-10 \\
4.98 \mathrm{e}-13\end{array}$ & $4.98 \mathrm{e}-13$ & \\
\hline
\end{tabular}


The genus Thaparocleidus had a great species diversity in India and we could collect several of them, including a few new species. All the species described so far were primarily based on morphological basis. Some species are quite similar structurally. The use of these tools appeared very useful. Chaudhary and Singh $[3,4]$ have differentiated genera Thaparocleidus and Bifurcohaptor, using various tools. We tried to compare five species of one genus in the present work for the first time, using $28 \mathrm{~S}$ ribosomal region. The phylogenetic trees, primary as well as secondary results of sequence analysis confirmed that all the five species are genetically distinct and supported taxonomic approach (morphological identification).

\section{Acknowledgements}

We acknowledge the help received from our teacher Prof. K. C. Pandey. Facilities developed from UGC-SAP (DRS-I) programme under the thrust area "Helminth Taxonomy" of the Department of Zoology, University of Lucknow, utilized for the present work. We thank Head, Zoology for providing laboratory facilities. We also acknowledge UGC for the award of JRF (Endorsement no. 28943) and financial support to NA (F-4-10/2010 BSR).

\section{REFERENCES}

[1] B. Billoud, M.A. Guerrucci, M. Masselot, J.S. Deutsch. Cirripede phylogeny using a novel approach: molecular morphometrics, Molecular Biology and Evolution, Vol. 17, $1435-1445,2000$.

[2] V. Tandon. Molecular taxonomy of trematodes parasites-protocols to follow. Manual of the workshop on fish-parasites-taxonomy capacity building. Andhra University, Visakhapatnam, India 79-86, 2007.

[3] A. Chaudhary, H.S. Singh, Secondary structure and phylogenetic utility of the ribosomal large subunit (28S) in monogeneans of the genus Thaparocleidus and Bifurcohaptor (Monogenea: Dactylogyridae), Journal of Parasitic Disease, Vol. 37, 74-83, 2012a.

[4] A. Chaudhary, H.S. Singh, Description of two new species of genus Thaparocleidus Jain, 1952 (Monogenea: Dactylogyridae) from freshwater fishes in India: genetic and morphological evidence with application of the secondary structure model of rRNA for phylogeny, Journal of Helminthology, Vol. 87, 160-170, 2012b.

[5] H.R. Chiary, A. Chaudary, H.S. Singh, Phylogenetic analysis of the Dactylogyroides longicirrus (Monogenea: Dactylogyridae) based on the $18 \mathrm{~S}$ and ITS 1 ribosomal genes, Bioinformation, Vol. 9, No. 5, 250-254, 2013.

[6] A. Dubey, A.K. Gupta, S.M. Agrawal, Studies on monogenean parasites in freshwater fishes at Raipur VIII. Validity of Parancylodiscoides Achmerow, 1964 (Silurodiscoides, Gusev, 1974) and two new species from Raipur, Indian Journal Helminthology, Vol. 44, 9-16, 1992.
[7] Y. Desdevises, S. Morand, O. Jousson, P. Legendre, Co evolution between Lamellodiscus (Monogenea: Diplectanidae) and Sparidae (Teleostei): the study of a complex host-parasite system, Evolution, Vol. 56, 2459-2471, 2002 .

[8] A.V. Gusev, Freshwater Indian Monogenoidea. Principles of systematics, analysis of the world faunas and their evolution, Indian Journal Helminthology, Vol. 25-26, 1-241, 1976.

[9] A. Grajales, C. Aguilar, J, Sanchez, Phylogenetic reconstruction using secondary structures of internal transcribed spacer 2 (ITS2, rDNA): finding the molecular and morphological gap in Caribbean gorgonian corals, BMC Evolution Biology, Vol. 7, No. 90, 2007.

[10] T. Kulkarni, Studies on the monogenetic trematodes of fishes found in Hyderabad, Andhra Pradesh (India) Part II, Rivista De Parasitologia, Vol. 30, No. 4, 263-281, 1969.

[11] D.C. Kritsky, V.E. Thatcher, W.A. Boeger, Neotropical Monogenea 8. Reveision of Urocleidoides (Dactylogyridae, Ancyrocephalinae), Proceedings of Helminthological Society of Washington, Vol. 53, No. 1, 1-37, 1986.

[12] L.H.S. Lim, Thaparocleidus Jain, 1952, the senior synonym of Silurodiscoides Gussev,1976 (Monogenea:Ancylodiscoidinae), Systematic Parasitology, Vol. 35, 207-215, 1996.

[13] L. Plaisance, D.T.J. Littlewood, P.D. Olson, S. Morand, Molecular phylogeny of gill monogeneans (Platyhelminthes, Monogenea, Dactylogyridae) and colonization of Indo-West pacific butterflyfish hosts (Perciformes, Chaedontidae), Zoologica Scripta, Vol. 34, 425-436, 2005.

[14] A. Simkova, L. Plaisance, I. Matejusova, S. Morand, O. Verneau, Phylogenetic relationships of the Dactylogyridae Bychowsky, 1933 (Monogenea: Dactylogyridea): the need for the systematic revision of the Ancyrocephalinae Bychowsky, 1937, Systematic Parasitology, Vol. 54, 1-11, 2003.

[15] A. Simkova, I. Matejusova, C.O. Cunningham, A molocular phylogeny of the Dactylogyridae sensu Kritsky and Boeger (1989) (Monogenea) based on the D1-D3 domains of large subunit rDNA, Parasitology, Vol. 133, 43-53, 2006.

[16] J. Schultz, S. Maisel, D. Gerlach, T. Mueller, M. Wolf, A common core of secondary structure of the internal transcribed spacer 2 (ITS2) throughout the Eukaryota, RNA, Vol. 11, 361-364, 2005.

[17] C. Smith, S. Heyne, A.S. Richter, S. Will, R. Backofen, Freiburg RNA Tools: a web server integrating IntaRNA, ExpaRNA and LocARNA, Nucleic Acids Research, Vol. 38, W373-W377, 2010.

[18] L. Timothy, Bailey, C. Elkan, Fitting a mixture model by expectation maximization to discover motifs in biopolymers, Proceedings of the Second International Conference on Intelligent Systems for Molecular Biology, AAAI Press, Menlo Park, California 28-36, 1994.

[19] J.D. Thompson, D.G. Higgins, T.J. Gibson. Clustal W: Improving the sensitivity of progressive multiple sequence alignment through sequence weighting, positions- specific gap penalties and weight matrix choice, Nucleic Acids Research, Vol. 22, 4673-4680, 1994.

[20] K. Tamura, D. Peterson, N. Peterson, G. Stecher, M. Nei, S. 
Kumar. MEGA5: Molecular Evolutionary Genetics Analysis using Maximum Likelihood, Evolutionary Distance, and Maximum Parsimony Methods, Molecular Biology and Evolution, Vol. 28, 2731-2739, 2011.

[21] S. Will, K. Reiche, I.L. Hofacker, F.S. Peter, R. Backofen. Inferring non-coding RNA families and classes by means of genome-scale structure-based clustering, PLoS Computational Biology, Vol. 3, No. 4, e65, 2007.

[22] S. Will, I.T. Josh, I.L. Hofacker, P.F. Stadler, R. Backofen. LocARNA-P: Accurate boundary prediction and improved detection of structural RNAs, RNA, Vol. 18, No. 5, 900-914, 2012.

[23] S. Rajvanshi, N. Agrawal. One known and unknown species of of the genus Thaparocleidus, Jain, 1952, infecting Sperata aor (Hamilton, 1822): Camparison with species from China, on molecular basis. Bioinformation, 9 (11), 577-582, 2013.

[24] C. Zwieb, C. Glotz, R. Brimacombe. Secondary structure comparisons between small subunit ribosomal RNA molecules from six different species, Nucleic Acids Research, Vol. 9, 3621-3640, 1981.

[25] M. Zuker. Mfold web server for nucleic acid folding and hybridization prediction, Nucleic Acids Research, Vol. 31, No. 13, 3406-3415, 2003.

[26] http://www.genomicsplace.com/gc_calc.html

[27] www.iucnredlist.org Downloaded on 11 March 2013

[28] www.fishbase.org, version (04/2013) 